\title{
Políticas e permanência para estudantes na educação superior
}

\author{
Policies and continuity for students in higher education \\ Políticas y permanencia para estudiantes en la educación superior
}

\section{CARINA ELISABETH MACIEL ELIZETH GONZAGA DOS SANTOS LIMA FELIPE VIEIRA GIMENEZ}

\begin{abstract}
Resumo: O presente artigo tem por objetivo analisar as políticas de permanência nas Instituições Federais e Estaduais de Educação Superior - IES, a partir de estudo realizado com as seguintes universidades: Universidade Federal de Mato Grosso do Sul - UFMS, Universidade Federal de Mato Grosso - UFMT, Universidade Federal da Grande Dourados - UFGD, Universidade Estadual de Mato Grosso do Sul - UEMS e Universidade do Estado de Mato Grosso - UNEMAT. Para o desenvolvimento da pesquisa analisaram-se ações e programas desenvolvidos pelas IES em destaque. Os dados foram coletados por meio de documentos institucionais e nacionais. Resultados indicam ações desenvolvidas com base em orientações nacionais e estaduais que se materializam como ações que apontam que a expansão universitária pode ampliar o acesso da população à educação superior. Com efeito, as políticas de permanência nas IES são identificadas como estratégias para minimizar os efeitos da desigualdade social e seguem as orientações do Plano Nacional de Assistência Estudantil - PNAES e Programa Nacional de Assistência Estudantil para as Universidades Estaduais - PNAEST, sendo preciso compreender vários fatores que interferem na permanência do estudante em seus respectivos cursos de graduação.
\end{abstract}

Palavras-chave: Educação Superior; Políticas Educacionais; Permanência.

Abstract: This article aims to analyze the permanency policies in Federal and State Institutions of Higher Education (HEIs). It bases from a study conducted with the following universities: Federal University of Mato Grosso do Sul (UFMS), Federal University of Mato Grosso (UFMT), Federal University of Grande Dourados (UFGD), State University of Mato Grosso do Sul (UEMS) and State University of Mato Grosso (UNEMAT). For the development of the research, we analyzed actions and programs developed by the HEIs in particular. We collected the data through institutional and national documents. Results indicate developed action based on state and national guidelines that materialize as actions that indicate that the university expansion can increase the population's access to higher education. Indeed, the permanency policies in HEIs are identifies as strategies to minimize the effects of social inequality and follow the guidelines of the National Plan of Student Assistance - PNAES and 
the National Program of Student Assistance for State Universities - PNAEST, being necessary to comprehend several factors that interfere with the student's stay in their respective undergraduate courses.

Keywords: Higher Education; educational policies; permanence.

Resumen: El presente artículo tiene como objetivo analizar las políticas de permanencia en las Instituciones Federales y Estatales de Educación Superior (IES), mediante un estudio realizado con las siguientes universidades: Universidad Federal de Mato Grosso do Sul - UFMS, Universidad Federal de Mato Grosso - UFMT, Universidad Federal de Grande Dourados - UFGD, Universidad del Estado de Mato Grosso do Sul - UEMS y Universidad del Estado de Mato Grosso - UNEMAT. Para el desarrollo de la investigación, fueron analizados programas y acciones desarrollados por las IES mencionadas. Los datos fueron recopilados por medio de documentos institucionales y nacionales. Los resultados indican acciones desarrolladas basadas en orientaciones nacionales y estatales que se materializan como acciones que apuntan que la expansión universitaria puede ampliar el acceso de la población a la Educación Superior. Efectivamente, las políticas de permanencia en las IES son identificadas como estrategias para minimizar los efectos de la desigualdad social y siguen las orientaciones del Plan Nacional de Asistencia al Estudiante - Pnaes y Programa Nacional de Asistencia para Estudiantes de Universidades Estatales - PNAEST, siendo necesario comprender diversos factores que interfieren en la permanencia del estudiante en sus respectivas carreras universitarias.

Palabras clave: Educación Superior; Políticas Educacionales; Permanencia.

\section{INTRODUÇÃO}

O presente artigo tem por objetivo analisar as políticas de permanência nas Instituições de Educação Superior (IES), a partir de um estudo que abrange a Universidade Federal de Mato Grosso do Sul (UFMS), a Universidade Federal de Mato Grosso (UFMT), a Universidade Federal da Grande Dourados (UFGD), a Universidade Estadual de Mato Grosso (UNEMAT) e a Universidade Federal de Mato Grosso do Sul (UFMS). Pesquisadores participantes da Rede Universitas/ $\mathrm{Br}{ }^{1}$ realizam a presente pesquisa, que se vincula à pesquisa interinstitucional Políticas de Expansão da Educação Superior no Brasil, ligada ao programa de fomento à pesquisa Observatório da Educação (CAPES).

O procedimento metodológico do estudo que ora se apresenta teve como recurso a pesquisa bibliográfica, bem como a coleta de dados e informações sobre

1 A Rede Universitas/Br caracteriza-se como uma rede acadêmica que conta com pesquisadores de Universidades e de diferentes Instituições de Ensino Superior (IES) de todas as regiões do país, visando à pesquisa e à interlocução entre pares que têm em comum a área do conhecimento Políticas de Educação Superior. A Rede congrega pesquisadores do Grupo de Trabalho (GT 11) - Política de Educação Superior da Associação Nacional de Pós-Graduação e Pesquisa em Educação (ANPED) e de várias IES do país. 
as IES no Censo da Educação Superior e bancos de dados específicos das IES investigadas, além de outras informações por estas disponibilizadas.

Inicialmente, cabe ressaltar que as ações de permanência nas IES que são objeto deste estudo estão relacionadas à política de assistência estudantil que, segundo consta do documento do Programa Nacional de Assistência Estudantil (PNAES), visa a garantir o sucesso acadêmico com a conclusão do curso de graduação, inferindo-se que seja capaz de diminuir os índices de retenção e evasão decorrentes de fatores socioeconômicos.

As ações de assistência estudantil são desenvolvidas de acordo com os objetivos e diretrizes do Programa Nacional de Assistência Estudantil (PNAES) ${ }^{2}$, a partir do Decreto $n^{0}$ 7.234, de 19 de julho de 2010, que tem por finalidade ampliar as condições de permanência dos jovens na Educação Superior na esfera pública federal. Nas universidades estaduais, o Programa Nacional de Assistência Estudantil para as Instituições de Educação Superior Públicas Estaduais (PNAEST) foi instituído pela Portaria Normativa $n^{\circ} 25$, de 28 de dezembro de 2010 (BRASIL, 2010c).

A fim de desenvolver o tema em pauta, no primeiro momento, apresentamos a educação como direito social. Posteriormente, evidenciamos a principal tendência da expansão da Educação Superior no Brasil a partir dos dados do Censo da Educação Superior de 2014; em seguida, apresentamos os programas de permanência das IES pesquisadas.

Assim, é oportuno observar que "O esforço dos agentes envolvidos no campo da educação superior pública dando centralidade nas discussões dos elementos importantes para a permanência do estudante na universidade pública é pauta contemporânea e objeto de reflexão". (NUNES; VELOSO, 2015, p. 817). Permanecer na educação superior e conclui-la são ações determinadas por vários elementos e envolvem recursos humanos e econômicos, conjunto que representa, cada vez mais, esforços institucionais e o desenvolvimento de políticas específicas para favorecer o sucesso dos estudantes da Educação Superior pública. Dessa forma, as políticas de permanência são identificadas por uma perspectiva que não se encerra nas ações de assistência estudantil, mas abarcam os aspectos de infraestrutura, física e tecnológica, e das condições didático-pedagógicas proporcionadas aos estudantes nas IES.

2 Art.1o O Programa Nacional de Assistência Estudantil (PNAES), executado no âmbito do Ministério da Educação. Decreto no 7.234, de 19 de julho de 2010 (BRASIL, 2010b). Dispõe sobre o Programa Nacional de Assistência Estudantil (PNAES). Disponível em: <http://www.planalto.gov.br/ccivil_03/_ato20072010/2010/decreto/d7234.htm>. Acesso em: 21 abr. 2016. 


\section{POLÍTICAS E EDUCAÇÃO SUPERIOR: ASPECTOS HISTÓRICOS E REGULATÓRIOS}

A Educação Superior é parte do processo da formação humana e está relacionada com a história da sociedade. Na Declaração Mundial sobre Educação Superior no século XXI, esta é identificada como "Todo tipo de estudos, treinamento ou formação para pesquisa em nível pós-secundário, oferecido por universidades ou outros estabelecimentos educacionais aprovados como instituições de educação superior [...] competentes do Estado”. (UNESCO, 1998, p. 2).

Segundo o artigo no 205 da Constituição Federal (CF) de 1988 (BRASIL, 2010a), a educação é caracterizada como direito de todos e dever do Estado e da família, sendo incentivada e promovida por meio do coletivo, ou seja, trata-se de diferentes elementos cuja relação é determinante, envolvendo família, Estado e sociedade. No artigo no 211, a CF responsabiliza União, estados, Distrito Federal e municípios pela organização de seus sistemas de ensino no que diz respeito à oferta e ao financiamento. Igualmente, estabelece a parcela de contribuição e responsabilidade de cada ente da Federação e do Estado para a garantia e efetivação desse direito.

Outros documentos jurídicos que também contêm elementos a respeito do direito à educação são: Lei de Diretrizes e Bases da Educação Nacional (LDB), Estatuto da Criança e do Adolescente (ECA), Plano Nacional de Educação (PNE) e Pacto Internacional sobre os Direitos Econômicos, Sociais e Culturais. Assim, o direito à educação é reconhecido nacional e internacionalmente.

Segundo as diretrizes dos Direitos Humanos, "A educação se revela como um elemento essencial para a formação do cidadão enquanto sujeito de direitos. Isto é, aquela pessoa que se sente responsável pelo projeto de sociedade à qual pertence”. (BRASIL, 2013, p. 34). A educação é um direito e as políticas de acesso e permanência têm como objetivo a garantia deste:

\footnotetext{
No Brasil, a discussão sobre a Educação em Direitos Humanos se fortaleceu nos fins da década de 1980 por meio dos processos de redemocratização do país e das experiências pioneiras que surgiram entre os profissionais liberais, universidades e organizações populares na luta por esses direitos. [...] A Década da ONU para EDH teve início em janeiro de 1995, e em julho de 2003 o Estado brasileiro tornou oficial a Educação em Direitos Humanos como política pública com a constituição do Comitê Nacional de Educação em Direitos Humanos (CNEDH). Esse Comitê reúne especialistas da área e teve como primeira missão elaborar o PNEDH, objetivando estimular o debate sobre os direitos humanos e a formação para a cidadania no Brasil. (Idem, p. 30-32).
} 
Na contemporaneidade, a educação em Direitos Humanos representa um campo de lutas e conquistas sociais, pois a principal característica do ensino no Brasil foi marcada pela permanência do elitismo e da seletividade, principalmente no que se refere ao campo da educação superior.

Devido a que o acesso à Educação Superior é limitado por diversos fatores, como a desigualdade social, a renda familiar, a cor/etnia, os fatores socioeconômicos e culturais, Sguissardi (2014) afirma que a elitização desse nível de educação continua com dados preocupantes:

"o principal fator de produção do elitismo da ES neste país: mais de $89 \%$ dos
jovens de 18 a 24 anos ainda não têm acesso à Educação Superior e menos de
$5 \%$ dos jovens de 24, ingressam na pós-graduação stricto sensu". (SGUISSARDI,
2014 , p. 72). Com efeito, a educação se configura como direito social, contudo,
"O objetivo dos direitos sociais é corrigir desigualdades próprias das sociedades
de classe, aproximando grupos ou categorias marginalizadas". (DUARTE, 2007,
p. 698).

Com a intenção declarada de organizar e melhorar o desenvolvimento da educação são elaborados decretos, leis e textos constitucionais que normatizam, orientam e regulamentam esse direito, estabelecendo suas diretrizes em dado contexto. Segundo Cury (2002),

Diretrizes são linhas gerais que, assumidas como dimensões normativas, tornam-se reguladoras de um caminho consensual, conquanto não fechado a que historicamente possa vir a ter um outro percurso alternativo, para se atingir uma finalidade maior. Nascidas do dissenso, unificadas pelo diálogo, elas não são uniformes, não são toda a verdade, podem ser traduzidas em diferentes programas de ensino e, como toda e qualquer realidade, não são uma forma acabada de ser (p. 193).

Os documentos elaborados e aprovados assumem dimensão normativa, um caminho proposto, um rumo ou uma direção no sentido de dar um norte consensual para se atingir uma finalidade maior, o que se expressa pela implementação de políticas educacionais.

Considerando o desenvolvimento desses documentos por meio de diferentes coletivos, entendemos que as políticas educacionais começam a ganhar força no Brasil a partir de dois importantes marcos. Primeiro, o marco da Constituição Federal, conhecida como a "Constituição Cidadã", que, segundo Santos (2011), parece consolidar várias conquistas de direitos, ao mesmo tempo em que anuncia mecanismos democratizadores e descentralizadores das políticas sociais, na direção do fortalecimento da responsabilidade social do Estado. Dentre os direitos que se ampliam, destaca-se o da educação. O segundo marco define- 
se a partir da década de 1990, com a aprovação da Lei 9.394/1996 (BRASIL 1996), de Diretrizes e Bases da Educação Nacional (LDB), amplamente discutida e debatida em diversas instâncias políticas.

Os dois marcos podem ser identificados como projetos nacionais que intencionam influenciar os rumos da educação no país. Entretanto, ao longo dos anos, foram sendo alterados, afetando sua materialização, a exemplo de políticas desdobradas em diferentes programas e documentos, favorecendo ajustes e reajustes necessários às adequações econômicas e sociais de uma sociedade cada vez mais submetida ao grande capital.

Lima, Marques e Silva (2009) afirmam que as articulações sobre o movimento educacional mundial consistem em adequá-lo à reestruturação do modo de produção capitalista. Conclui em sua análise:

Enfim, tratava-se, na década de 1990 de tentar solucionar os problemas cumulativos de décadas anteriores, como as vagas reprimidas, a inadequação do fluxo escolar e os altos índices de reprovação, discrepância no financiamento da Educação Básica e da Educação Superior. (p. 182-183).

Lima (2012) ressalta que, nesse cenário, a educação era entendida como subsidiária da política econômica, portanto, um problema da economia. Postulava-se, assim, uma política econômica como uma política não social, na medida em que, em nosso entendimento, existe uma relação primordial entre política educacional, economia e a social. Divorciá-las em patamares diferentes e opostos significa estabelecer um viés economicista às políticas sociais, incluindo nessas a educação, a saúde, a segurança, a previdência, entre outras.

Segundo Melo, Santos e Andrade (2009),

A história da educação superior no Brasil não pode ser analisada sem considerar-se sua relação com o desenvolvimento sócio-histórico brasileiro. A história de nossa sociedade é marcada pelo elitismo e pela exclusão, com implicações semelhantes em nossa educação e consequentemente no ensino superior. Do período colonial, passando pelo Império até a Primeira República, os projetos e iniciativas no campo do ensino superior evidenciaram esses dois traços: um ensino voltado para as elites, para aqueles que podiam pagar e uma série de obstáculos e mecanismos que excluíam a maior parte da população do acesso ao nível superior (p. 10).

Com efeito, a Educação Superior brasileira, desde a chegada da família real à Colônia em 1808, foi pensada para uma elite, estendendo-se esse ideário ao período monárquico e republicano. Denota uma política de controle criada não para atender às necessidades de ampliação do conhecimento da sociedade, 
mas um bem cultural oferecido a grupos específicos e privilegiados e que, em nenhuma hipótese, visou a constituir um espaço de investigação científica e de produção de conhecimento.

Nessa conjuntura, a materialização da Educação Superior por meio de políticas de Estado $^{3}$ representa na contemporaneidade a efetivação de ganhos e garantias de direito social.

A seguir, apresentamos a expansão da Educação Superior no Brasil a partir da análise dos dados do Censo da Educação Superior, como uma das ações resultantes dos governos dos anos de 1995 até 2014.

\section{POLÍTICA DE EXPANSÃO NA EDUCAÇÃO SUPERIOR}

É no período pós-LDB (Lei no 9.394/1996) que se observa forte expansão da Educação Superior no Brasil, principalmente no nível de graduação. Nesse sentido, a abertura das IES do setor privado ao capital encontrou um campo propício para sua ampliação, o que irrompeu no governo de Fernando Henrique Cardoso (FHC) (1995-2002) e teve continuidade no governo Luiz Inácio da Silva (2003-2010) e no primeiro mandato de Dilma Rousseff (2011-2014). Tal movimento promoveu a expansão da Educação Superior, com destaque ao setor privado com fins lucrativos.

Segundo Mancebo, Vale e Martins (2015), a expansão engendrada nas últimas décadas pode ser percebida como positiva por ter ampliado o acesso da população à Educação Superior. Deve-se atentar, entretanto, para alguns efeitos perversos desse processo, particularmente no que tange ao perfil dos cursos e das carreiras criados pelas instituições privadas, cuja expansão se dá sob a influência direta de demandas mercadológicas, valendo-se dos interesses da burguesia desse setor em ampliar a valorização de seu capital com a venda de serviços educacionais.

Sendo assim, a abertura de novas vagas nas IES públicas e privadas, as novas formas de ingresso, a abertura de vagas para cursos noturnos, os novos cursos e modalidades, os programas de intercâmbio e a abertura de novos campi na esfera federal demarcam o presente século XXI com a predominância de políticas de expansão do sistema público federal e, concomitantemente, do setor privado.

Nesse cenário, registra-se a redefinição do papel do Estado, que promove a política de mercantilização do nível superior. Chaves e Amaral (2013) explicam que a política privatista adotada pelo governo federal foi reforçada por meio da

3 Segundo Oliveira (2011), as políticas de Estado são aquelas que envolvem mais de uma agência do Estado, passando em geral pelo Parlamento ou por instâncias diversas de discussão, resultando em mudanças de outras normas ou disposições preexistentes, com incidência em setores mais amplos da sociedade. 
Lei nº 5.172/1966, que instituiu o Código Tributário Nacional, em vigor até hoje, que se concretizou mediante inúmeras ações que favorecem o setor privado, em especial pela concessão de isenções fiscais ${ }^{4}$. Como resultado, as instituições de ensino sem fins lucrativos têm-se beneficiado de uma série de incentivos fiscais garantidos via renúncia tributária, seja pela isenção total de impostos e contribuições, seja pela redução de suas alíquotas.

Esse crescimento é extremamente complexo. Além de compreender um ininterrupto crescimento de instituições de Educação Superior (IES) privadas com fins lucrativos, registramos a iniciativa pública, em especial do governo federal, que expande vagas e multiplica o número de instituições, com destaque para o Programa de Apoio a Planos de Reestruturação e Expansão das Universidades Federais (REUNI) ${ }^{5}$ e uma grande expansão da pós-graduação, com redefinição de seus rumos. "O maior projeto público de expansão da educação superior, no período em estudo, foi o REUNI, sendo o responsável pelo aumento de 60,05\% das matrículas presenciais na rede federal, entre 2007 e 2012." (MANCEBO, 2015, p. 151).

Essa autora aponta que, entre os anos de 1995 e 2010, a expansão de matrículas tem maior expressão no setor privado, com crescimento de 347,15\%, ao mesmo tempo em que o crescimento de matrículas nas IES públicas aumenta apenas 134,58\% (MANCEBO; VALE; MARTINS, 2015). Destaca, ainda, as críticas ao REUNI, que envolve o aumento do número de estudantes sem o necessário incremento do número de professores e técnicos, o que tem intensificado sobremodo o trabalho docente. Ademais, questiona os recursos destinados à construção da estrutura física, insuficientes para o atendimento da expansão em curso e para a qualidade das atividades acadêmicas.

Segundo o INEP (2015), destacam-se os seguintes números:

Em 2014, 32.878 cursos de graduação foram ofertados em 2.368 instituições de educação superior no Brasil. [...] Em 2014 foram oferecidas mais de 8 milhões de vagas pelas IES brasileiras, sendo $78,5 \%$ de vagas novas e $90,2 \%$ em instituições privadas. A rede Federal ofereceu 343 mil novas vagas e 114 mil vagas remanescentes

4 Imposto de Renda das Pessoas Jurídicas, Contribuição Social sobre o Lucro Líquido, instituída pela Lei no 7.689, de 15 de dezembro de 1988, Contribuição Social para Financiamento da Seguridade Social, instituída pela Lei Complementar no 70, de 30 de dezembro de 1991. Contribuição para o Programa de Integração Social, instituída pela Lei Complementar no 7, de 7 de setembro de 1970.

5 Decreto $n^{\circ}$ 6.096, de 24 de abril de 2007, que institui o Programa de Apoio a Planos de Reestruturação e Expansão das Universidades Federais (Reuni). Em seu artigo 1o, fica instituído o Programa de Apoio a Planos de Reestruturação e Expansão das Universidades Federais (Reuni) com o objetivo de criar condições para a ampliação do acesso e permanência na Educação Superior, no nível de graduação, pelo melhor aproveitamento da estrutura física e de recursos humanos existentes nas universidades federais. 
para ingresso em cursos de graduação. [...] Em 2014, mais de 3,1 milhões de alunos ingressaram em cursos de educação superior de graduação. Deste total, 82,3\% em instituições privadas (p. 17-20).

A evolução das matrículas na Educação Superior no Brasil, a partir de 1996 até 2014, pode ser observada no Gráfico 1, que permite análises a partir das taxas que consideram os alunos de graduação presencial.

Gráfico 1 - Evolução de matrículas nos cursos de graduação por categoria administrativa (pública e privada) no Brasil - 1996 a 2014

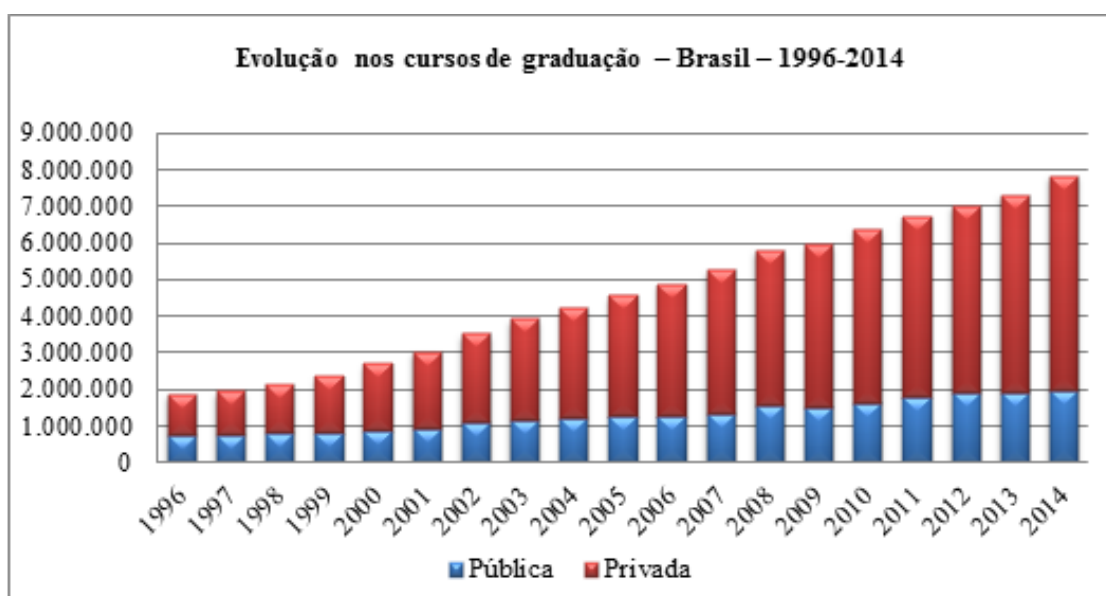

Fonte: INEP, 2015.

Observa-se que a taxa de crescimento da rede privada, comparando o ano de 2013 ao de 2014, apresentou crescimento nas matrículas de graduação presencial de $9 \%$. Na rede pública, praticamente não houve crescimento, apresentando-se uma estagnação, embora, se comparada à rede privada haja queda de 19\%. A rede privada, no ano de 2014, alcançou um incremento de novas matrículas de 493.561; por sua vez, a rede pública teve 28.475 , ou seja, foram aproximadamente 465.086 matrículas a mais no setor privado.

No próximo item será apresentada a expansão das políticas e programas de permanência a partir do PNAES nas Instituições de Educação Superior.

\section{PROGRAMAS DE PERMANÊNCIA PARA ESTUDANTES NAS UNIVERSIDADES: UFMS, UFMT, UFGD, UNEMAT E UEMS}

Conforme exposto, a Educação Superior passou por processos de mudança nos últimos vinte anos, o que ocorreu praticamente em todo o mundo. 
O termo expansão, em sua concepção, precisa ser analisado nesse contexto. Silva e Nogueira (2011) afirmam, nessa perspectiva:

Concebe-se expansão e acesso à educação superior como fenômenos interligados, com reflexos mútuos, razão porque, neste trabalho, são evidenciados de forma integrada. Por acesso entende-se a participação na educação superior, o que implica, idealmente, em considerar as dimensões de ingresso, permanência, conclusão e formação/qualidade desse nível de ensino (SILVA; NOGUEIRA, p. 14, grifos nossos).

As autoras, nesse sentido, discutem a expansão e o acesso de forma integrada. A propósito, na medida em que o estudante é aprovado no processo seletivo e efetiva sua matrícula, obtém seu passaporte de ingresso na universidade pública, podendo ocorrer também o oposto, o não preenchimento das vagas, gerando as chamadas "vagas ociosas". Esse possível fenômeno, portanto, vinculase a outros, como a permanência, a conclusão e a qualidade na formação.

Em 2007, o Plano Nacional de Assistência Estudantil foi aprovado pela Associação Nacional dos Dirigentes das Instituições Federais de Ensino Superior (Andifes), em julho, na cidade de Belém/PA. Esse fato deu início a um processo de discussão junto ao Ministério da Educação (MEC) no sentido da implantação do Programa Nacional de Assistência Estudantil. O MEC, considerando a assistência estudantil como estratégia de combate às desigualdades sociais e regionais, bem como importante para a ampliação e a democratização das condições de acesso e permanência dos jovens na faixa etária de 18 a 24 anos na Educação Superior, instituiu, por meio da Portaria Normativa no 39, de 12 de dezembro de 2007, o Programa Nacional de Assistência Estudantil (PNAES).

Posteriormente, o Decreto $n^{\circ}$ 7.234, de 19 de julho de 2010 (BRASIL, 2010b) institui o PNAES das universidades federais, que tem como finalidade ampliar as condições de permanência dos jovens na Educação Superior pública federal. Dentre os objetivos, destacam-se:

I - democratizar as condições de permanência dos jovens na educação superior pública federal; [...] II - minimizar os efeitos das desigualdades sociais e regionais na permanência e conclusão da educação superior; [...]

III - reduzir as taxas de retenção e evasão; e IV - contribuir para a promoção da inclusão social pela educação. (p. 1).

Ainda serão atendidos no âmbito do PNAES, segundo o art. $5^{\circ}$, prioritariamente, estudantes oriundos da rede pública de Educação Básica ou com renda familiar per capita de até um salário mínimo e meio.

Nesse sentido, as ações de assistência estudantil do PNAES deverão ser desenvolvidas em dez áreas específicas: moradia estudantil; alimentação; 
transporte; atenção à saúde; inclusão digital; cultura; esporte; creche; apoio pedagógico e acesso, participação e aprendizagem de estudantes com deficiência, transtornos globais do desenvolvimento e altas habilidades e superdotação.

Por sua vez, segundo o inciso $2^{\circ}$ do artigo terceiro: “Caberá à instituição federal de ensino superior definir os critérios e a metodologia de seleção dos alunos de graduação a serem beneficiados". (BRASIL, 2010b).

A partir desse quadro geral podemos identificar as políticas de permanência que integram a assistência estudantil vigentes na UFMS, UFMT e UFGD, conforme apresentamos, a seguir, no Quadro 1.

\section{Quadro 1 - Políticas e Programas de permanência nas IFES}

\begin{tabular}{|c|c|c|}
\hline \multicolumn{3}{|c|}{ Programas de Permanência nas Federais } \\
\hline UFMS & UFMT & UFGD \\
\hline $\begin{array}{l}\text { Bolsa Permanência UFMS } \\
\text { Bolsa Permanência do MEC } \\
\text { Auxílio Alimentação } \\
\text { Auxílio-Emergencial } \\
\text { Incentivo à participação em eventos } \\
\text { Suporte Instrumental - kit } \\
\text { Programa Institucional de Bolsas de } \\
\text { Iniciação Científica (PIBIC) e PIBICl } \\
\text { AF Ação Afirmativa } \\
\text { PIBID } \\
\text { PIBIT } \\
\text { PROMISAES } \\
\text { Ação de Atenção à Saúde do } \\
\text { acadêmico } \\
\text { Ação de Inclusão Digital }\end{array}$ & $\begin{array}{l}\text { Auxílio Permanência - PRAE } \\
\text { Auxílio Alimentação } \\
\text { Auxílio Moradia - PRAE } \\
\text { Programa de Acolhimento Imediato } \\
\text { Bolsa Apoio a Inclusão - PRAE } \\
\text { Cursos de música e línguas } \\
\text { (PROCEV) } \\
\text { Programa Institucional de Bolsas de } \\
\text { Iniciação Científica (PIBIC/AF) Ação } \\
\text { Afirmativa (PROPeq) } \\
\text { Programa de Educação Tutorial } \\
\text { (PET) Conexões de Saberes } \\
\text { (PROEG) } \\
\text { Auxílio a Evento Externo - PRAE } \\
\text { Monitoria - PROEG } \\
\text { Tutoria - PROEG } \\
\text { PIBID - PROEG } \\
\text { PIBIT - PROPeq }\end{array}$ & $\begin{array}{l}\text { Bolsa permanência UFGD } \\
\text { Bolsa permanência MEC } \\
\text { Auxílio Alimentação } \\
\text { Auxílio Moradia } \\
\text { Auxílio Emergencial } \\
\text { Apoio pedagógico } \\
\text { Participação em Eventos } \\
\text { Acadêmicos } \\
\text { Mobilidade Acadêmica Internacional } \\
\text { Apoio aos Acadêmicos Pais e Mães } \\
\text { Atendimento Psicossocial } \\
\text { Acessibilidade de estudantes } \\
\text { portadores de necessidades } \\
\text { especiais } \\
\text { Apoio Pedagógico (em } \\
\text { implementação) } \\
\text { Programa de acompanhamento } \\
\text { pedagógico (em implementacão) }\end{array}$ \\
\hline
\end{tabular}

Fonte: Gimenez; Maciel, 2016.

Com efeito, a Universidade Federal de Mato Grosso do Sul (UFMS), a Universidade Federal de Mato Grosso (UFMT) e a Universidade da Grande Dourados (UFGD), no desenvolvimento de suas ações de permanência, estão embasadas no PNAES.

$\mathrm{Na}$ UFMS e na UFGD, tanto a bolsa permanência institucional quanto a bolsa permanência do MEC perfazem o valor de $\mathrm{R} \$ 400,00$ mensais. Tal bolsa nas instituições tem por objetivo favorecer a permanência dos acadêmicos, visando àqueles com vulnerabilidade social. Percebe-se, ainda, que adotam como referência os valores das bolsas correspondentes pagas pelas agências oficiais de fomento à pesquisa.

A UFMT possui o auxílio permanência desde 2005, no valor de R\$ 400,00 mensais, que atende estudantes com baixa renda, os quais devem estar 
regularmente matriculados em cursos de graduação da UFMT, na modalidade presencial e cumprir uma carga horária 12 horas semanais como condição para participar e receber a bolsa, ou seja, marcada pela lógica da contrapartida, no cumprimento de obrigatoriedades institucionais.

O auxílio alimentação é concedido em todas as universidades federais pesquisadas, sendo destinado aos acadêmicos que provam, por meio de processo seletivo, a condição de alunos de baixa renda per capita de até um salário mínimo.

No caso da UFMS, o benefício é concedido por meio de um subsídio para o campus que possui restaurante universitário (RU); para os campi que não têm RU, o repasse é realizado por meio de auxílio financeiro diretamente aos estudantes. Na UFMT o valor é repassado aos estudantes, correspondendo ao valor do almoço e jantar cobrado pela instituição (R \$1,00). Na UFGD, o auxílio é mensal, no valor de $\mathrm{R} \$ 150,00$.

A moradia estudantil é desenvolvida de forma diferente em cada uma das universidades federais investigadas. Na UFMS, optou-se por substituir o auxílio moradia pela bolsa permanência. Na UFMT, o auxílio é pago independentemente da bolsa permanência, cujos valores são de $R \$ 400,00$, de maneira que são beneficiados os estudantes vindos de outros municípios. Trata-se de uma política denominada "acolhimento", ou seja, são destinados recursos àqueles acadêmicos que não residem na localidade na universidade.

A UFGD possui moradia física para os estudantes, isto é, eles não recebem valor algum, mas possuem obrigações quanto à estadia nos apartamentos e podem receber advertências pelo descumprimento das regras constantes no edital de seleção.

O auxílio emergencial ou apoio à inclusão são outros mecanismos que as universidades (UFMS, UFMT e UFGD) utilizam com o mesmo objetivo, a permanência dos estudantes. Ressaltamos que, na UFMT, esse apoio é destinado, especificamente, aos estudantes atendidos pelas políticas de ações afirmativas.

A UFMS, UFMT e UFGD, além dos programas bolsa permanência, auxílio alimentação e moradia, possuem outros que complementam suas políticas de assistência ao estudante, dentre os quais se destacam a iniciação científica, o apoio pedagógico, bem como cursos de línguas, incentivo à participação em eventos, mobilidade acadêmica, atendimento psicossocial, inclusão digital, bolsas de extensão, monitoria e tutoria. Na UFMS, identificamos o suporte instrumental-Kit, cujos cursos atendidos são: Artes visuais; Arquitetura e Urbanismo; Enfermagem (Cidade Universitária); Engenharia Civil; Engenharia Elétrica; Medicina e Música.

Assim, destacamos a relação do PNAES com as políticas de permanência desenvolvidas nas universidades federais desta pesquisa, ressaltando que os 
recursos financeiros para custeio e manutenção dos programas interferem na adoção deles e definem linhas de ação.

As ações de Assistência Estudantil são destinadas aos estudantes matriculados em
cursos presenciais de graduação e devem ser desenvolvidas pelas Ifes de forma
articulada com as atividades de ensino, pesquisa e extensão nas seguintes áreas:
moradia estudantil; alimentação; transporte; atenção à saúde; inclusão digital;
cultura; esporte; creche; apoio pedagógico; e, acesso, participação e aprendizagem
de estudantes com deficiência, transtornos globais do desenvolvimento e altas
habilidades e superdotação. As linhas de ação são apresentadas de forma genérica,
resguardando a autonomia universitária na definição de suas ações conforme o que
já existia ou na implantação de novas ações. (BORSATO, 2015, p. 103).

Nesse sentido, em 2010 o Ministério da Educação (MEC), em continuidade com a política de Assistência estudantil, instituiu, por meio da Portaria Normativa $\mathrm{n}^{\mathrm{o}}$ 25, de 28 de dezembro de 2010 (BRASIL, 2010c), o Programa Nacional de Assistência Estudantil para as instituições de educação superior públicas estaduais (PNAEST). O Programa apresenta a finalidade de ampliar as condições de acesso, permanência e sucesso dos jovens na Educação Superior pública estadual tendo como estratégia de combate às desigualdades sociais e regionais e de inclusão social que promova a garantia do pleno acesso, permanência e sucesso aos estudantes das universidades. (BRASIL, 2010c).

Com a implantação do PNAEST, houve ampliação dos programas de assistência estudantil, criando, principalmente, os auxílios alimentação e moradia, conforme previsto nas diretrizes do programa. Nos estudos de casos das IES, identificamos vários programas que consideramos de permanência, conforme demonstrado no quadro que segue. 


\section{Quadro 2- Políticas e Programas de Permanência nas Universidades Estaduais no período de 2012 a 2015}

\begin{tabular}{|c|c|}
\hline UNEMAT & UEMS \\
\hline $\begin{array}{ll}\text { - } & \text { Auxílio Moradia } \\
\text { - Auxílio Alimentação } \\
\text { acadêmico } & \text { Saúde (física e mental) - seguro } \\
\text { : } & \text { Auxílio financeiro - Bolsa apoio ao aluno } \\
\text { carente socioeconômico (Baixa renda) } \\
\text { especiais } & \text { Apoio a portadores de necessidades } \\
\text { : } & \text { Mobilidade acadêmica } \\
\text { Bolsa Foco } & \text { Bolsa - PIBID } \\
\text { - } & \text { Bolsa - PIBIC-CNPq } \\
\text { Bolsa - PIBIC-CNPq - AF } \\
\text { B } \\
\text { Bolsa - PROBIC } \\
\text { Bolsa Cultura - (Coral, Artes Plásticas, Banda Sinfônica, } \\
\text { Teatro, Cinema e etc.). }\end{array}$ & 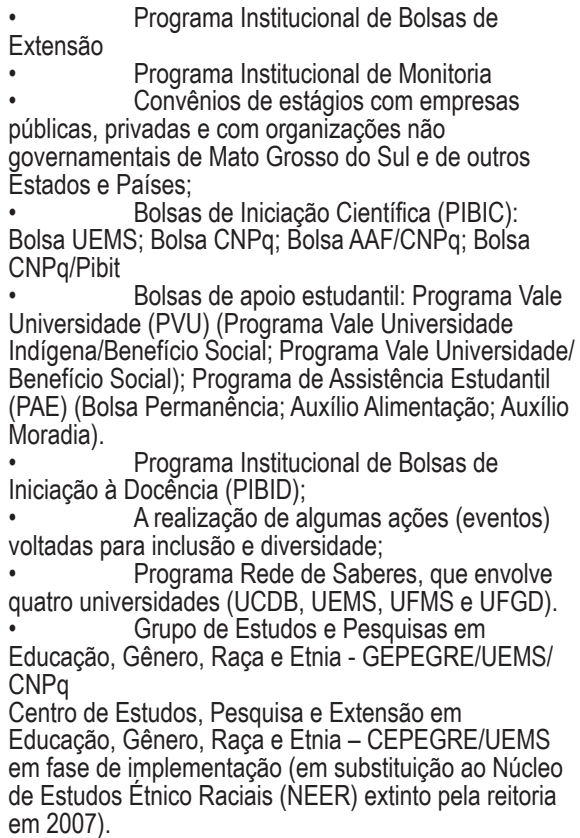 \\
\hline
\end{tabular}

Fonte: Maciel et al, 2015.

Com base nos dados, destacamos que a UNEMAT atende à política do PNAEST. As políticas de permanência na UNEMAT constituem um processo em construção, portanto, ainda não são consolidadas, pois continuam fortemente vinculadas, principalmente, à concessão de bolsas nas modalidades de bolsa estágio, bolsa extensão, bolsa apoio, bolsa iniciação à docência, bolsa tutoria, bolsa monitoria, bolsa PIBIC, bolsa PROBIC, bolsa Foco e bolsa de mobilidade acadêmica.

A partir de 2013, com a adesão ao Sistema de Seleção Unificada (Sisu), a UNEMAT começou a ter acesso a recursos de programas federais para implantação de políticas de permanência, por meio do PNAEST e implementa, por meio da Resolução 021/2013 do Consuni, o Programa de Auxílio para Moradia Estudantil e, ainda, pela Resolução 020/2013 Consuni, o Programa de Auxílio Alimentação. Nessas resoluções encontramos o termo permanência como caracterização dos programas.

A UNEMAT oferta bolsa apoio ao aluno carente. A moradia estudantil e o auxílio alimentação são ações que se destinam ao discente de graduação com 
comprovada vulnerabilidade e que esteja residindo em município diverso dos pais e cursando a primeira graduação. A instituição também oferece Bolsa Foco, destinada aos discentes regularmente matriculados. Ademais, oferece a Mobilidade Acadêmica, que destina apoio aos acadêmicos portadores de necessidades especiais, auxílio financeiro para participação em eventos, a bolsa PIBID, a bolsa estágio e a bolsa cultura.

No caso da UEMS, constatamos que esta conta com diferentes ações em sua política de permanência, como o Vale Universidade Indígena e o PNAEST, além das bolsas de iniciação científica (PIBIC), iniciação à docência (PIBID), bolsas ações afirmativas (AF) e bolsas de extensão. O Programa de Assistência Estudantil (PAE) é institucional oferta bolsas distribuídas nas seguintes modalidades: Bolsa Permanência, Auxílio-Alimentação, Auxílio-Moradia, bolsa monitoria e bolsa de extensão. A instituição realiza, ainda, ações (eventos) voltadas para inclusão e diversidade.

A UEMS segue a política do PNAEST, implementada por meio de ações de assistência estudantil articuladas às atividades de ensino, pesquisa e extensão para o atendimento de estudantes matriculados em cursos de graduação presenciais das instituições estaduais de ensino superior. Essas ações compreendem iniciativas desenvolvidas nas seguintes áreas: moradia estudantil, alimentação, transporte, assistência à saúde, inclusão digital, cultura, esporte, creche, apoio pedagógico, acesso, participação e aprendizagem de estudantes com deficiência, transtornos globais do desenvolvimento, altas habilidades e superdotação.

Na UEMS, são ofertadas as seguintes bolsas: Bolsas de Iniciação Científica (PIBIC), Bolsa UEMS, Bolsa CNPq, Bolsa AAF/CNPq, Bolsa CNPq/PIBIT e o Programa Vale Universidade Indígena (PVU). A IES possui os seguintes programas e grupos de estudos: Programa Rede de Saberes, que envolve quatro universidades (UCDB, UEMS, UFMS e UFGD); Grupo de Estudos e Pesquisas em Educação, Gênero, Raça e Etnia (GEPEGRE/UEMS/CNPq); Centro de Estudos, Pesquisa e Extensão em Educação, Gênero, Raça e Etnia (CEPEGRE/ UEMS), em fase de implementação (em substituição ao NEER, extinto pela reitoria em 2007). O auxílio financeiro, entre outras ações, é realizado por ambas as instituições, mas em contextos e perfis de estudantes diferentes.

\section{PERMANÊNCIA E ASSISTÊNCIA ESTUDANTIL: BUSCANDO NEXOS}

Segundo estudos de Borsato (2015), a Assistência Estudantil, no período anterior ao PNAES/PNAEST, ficou marcada pelas ações pontuais, muitas das quais dependiam, para sua realização, das parcerias estabelecidas com as fundações 
de apoio ou empresas, como é o caso da Bolsa-Alimentação e do AuxílioMoradia. Em virtude dos escassos recursos, a oferta de vagas era bem reduzida, não atendendo às demandas dos estudantes. As poucas ações implementadas eram focalizadas em atender o público com menor renda familiar e, nas IES em que existia a função de assistentes sociais, o trabalho desses era fazer a seleção dos estudantes para preenchimento das poucas vagas ofertadas.

Assim sendo, segundo Maciel et. al. (2015), já houve avanços nas conquistas e ganhos sociais. Embora a trajetória estudantil e seus desdobramentos ao longo da história tenham contribuído para o debate da inclusão, expansão e permanência, muitas lacunas ainda necessitam ser identificadas e analisadas.

Diante disso, entendemos que a permanência possui condicionantes externos e internos inerentes ao contexto do estudante. Maciel, Silva e Veloso (2015) ponderam: "cumpre assinalar o entendimento expresso em documentos nacionais de que a permanência do estudante na Educação Superior associa-se a investimentos na assistência estudantil" (p. 265). Logo, as políticas de permanência demandam grandes investimentos na área de seguridade social.

O direito à educação deve ser entendido como direito social de natureza coletiva. A educação é reconhecida nacional e internacionalmente como direito de qualquer indivíduo, pois os dispositivos mencionados em textos como a Constituição Federal de 1988, LDB, ECA, PNE, entre outros, ampliam os direitos de cidadania na direção do fortalecimento da responsabilidade social do Estado com a sociedade na elaboração e implementação de políticas educacionais.

Por conseguinte, os dados apresentados referentes à Educação Superior sobre matrículas e concluintes na graduação evidenciam números alarmantes, pois as metas e os objetivos propostos no REUNI, PROUNI E FIES possuem alcance abrangente, sendo considerados programas responsáveis pela expansão da Educação Superior no Brasil. Porém, as maiores taxas de matrículas e conclusão de curso entre os estudantes ainda ocorre na iniciativa privada, para a qual o Estado destina recursos que poderiam ser investidos nas universidades estatais públicas. No bojo de tais contradições emerge o problema da permanência, evasão e vagas ociosas, uma vez que, por exemplo, os estudantes ingressam por meio do Prouni ou Fies, mas faltam programas que lhes deem condições de permanência e conclusão de curso.

Dessa forma, a Assistência Estudantil, a partir do PNAES/PNAEST nas IES públicas, teve o papel de mobilizar recursos a fim de garantir a permanência mediante os programas de apoio ao estudante, caracterizado por ações institucionais das próprias universidades ou por meio de políticas, programas e ações do MEC. No caso das universidades pesquisadas (UFMS, UFMT, UFGD, UNEMAT e UEMS), as ações de permanência estão relacionadas à assistência 
estudantil, uma vez que essas IES atendem às determinações previstas nas normas do PNAES/PNAEST, documentos com orientação central para atender estudantes com vulnerabilidade econômica.

Continuamos analisando e questionando a ideia de permanência presente nas políticas do Estado, que leva em consideração sobretudo o determinante social e econômico.

Segundo Primão (2015),

\begin{abstract}
No que se refere às políticas de permanência instituídas, podemos observar que tanto o Estado, por meio dos seus programas específicos, quanto as pesquisas realizadas no tocante à permanência, estão centradas na realidade dos estudantes carentes, expressando-se na defesa de uma assistência quase exclusivamente financeira, como se esse fosse o único fator ameaçador do discente em seu trajeto universitário.
\end{abstract}

Embora o aspecto econômico seja importante para favorecer, ou não, a permanência do estudante em seu respectivo curso, partimos da premissa de que não seja o único ou o preponderante. Dessa forma, entendemos que as políticas assistencialistas focais são essenciais ao público de baixa renda; contudo, devese considerar a complexidade da questão que permeia a permanência. Segundo essa autora, o fator econômico inerente ao sistema capitalista cria a necessidade de políticas focais assistencialistas, e afirma que "a assistência estudantil, de fato, possui uma natureza focal” (PRIMÃO, 2015, p. 55). Ao se tratar do debate da permanência, mesmo reconhecendo os méritos de uma política assistencial, estrategicamente, almejamos uma política social de cunho universal, visto que esta se voltaria para ações mais abrangentes que generalizam o atendimento, o que pode possibilitar uma participação ativa de todos os estudantes na vida acadêmica.

\title{
CONSIDERAÇÕES FINAIS
}

A análise dos dados desta pesquisa aponta que as políticas e os programas de permanência são desenvolvidos para minimizar os efeitos da desigualdade social na Educação Superior, seguindo a lógica do discurso de inclusão ${ }^{6}$.

Cabe destacar que a expansão da esfera privada, a redução do papel do Estado e a ampliação das ações para a permanência na Educação Superior pública não são suficientes para garantir o acesso de todos a esse nível de educação. Segundo os dados do Censo da Educação Superior (2014), o índice de estudantes que não

\footnotetext{
6 O discurso da inclusão preconiza acesso aos direitos constitucionais a todos, pressupondo que cada sujeito tem méritos próprios que determinam seu sucesso ou fracasso, sem considerar que esse sujeito pertence à determinada classe social, condição econômica específica e que estes e outros fatores interferem no acesso aos seus direitos e na forma como desenvolve sua escolarização. Maciel (2009).
} 
concluem a graduação é expressivo, o que remete à necessidade do fortalecimento de políticas de permanência que levem em consideração as diversas causas da não permanência, como dificuldades de aprendizagem, dificuldade financeira, descontentamento acerca do método didático-pedagógico docente, transferência de domicílio, dificuldade em conciliar jornada de trabalho e horário do curso, cansaço, decepção pelas expectativas frustradas a respeito da instituição ou da profissão escolhida.

Com base nos dados desta pesquisa, é possível concluir que as ações destinadas à permanência dos estudantes seguem as orientações do PNAES e do PNAEST, ações que já representam um avanço. O destaque com relação à ausência de programas específicos que envolvam ações sistematizadas e individualizadas por curso ou com base em necessidades específicas dos estudantes, ressalta a necessidade de investimentos por parte das IES, com o objetivo de conhecer o perfil dos seus estudantes.

Persistem, como desafios, mais estudos e reflexões sobre o tema. Torna-se fundamental realizar estudos que proporcionem melhor entendimento das políticas de permanência, levando-se em conta os complexos fatores que promovem a permanência de estudantes nos cursos de graduação.

\section{REFERÊNCIAS}

BORSATO, Francieli Piva. A configuração da assistência estudantil na Universidade Federal de Mato Grosso do Sul após a implantação do PNAES. 2015. Dissertação (Mestrado em Serviço Social e Política Social) Universidade Estadual de Londrina, Londrina - UEL, 2015.

BRASIL. Secretaria de Direitos Humanos da Presidência da República. Educação em Direitos Humanos: Diretrizes Nacionais - Brasília: Coordenação Geral de Educação em SDH/PR, Direitos Humanos, Secretaria Nacional de Promoção e Defesa dos Direitos Humanos, 2013.

Lei $\mathrm{n}^{\circ}$ 5.172, de 25 de outubro de 1966. Dispõe sobre o Sistema Tributário Nacional e institui normas gerais de direito tributário aplicáveis à União, Estados e Municípios. Disponível em <https://www.planalto.gov.br/ ccivil_03/leis/L5172.htm>. Acesso em: 06 nov. 2016. 
. Lei no 7.689, de 15 de dezembro de 1988. Institui contribuição social sobre o lucro das pessoas jurídicas e dá outras providências. Disponível em <https://www.planalto.gov.br/ccivil_03/Leis/L7689.htm>. Acesso em: 06 nov. 2016.

Lei complementar $\mathrm{n}^{\circ} \mathbf{7 0}$, de 30 de dezembro de 1991. Institui contribuição para financiamento da Seguridade Social, eleva a alíquota da contribuição social sobre o lucro das instituições financeiras e dá outras providências.

Disponível em <http:// www.planalto.gov.br/ccivil_03/leis/LCP/Lcp70.htm>. Acesso em: 06 nov. 2016.

. Lei complementar $\mathrm{n}^{\circ} 7$, de 7 de setembro de 1970. Institui o Programa de Integração Social, e dá outras providências. Disponível em <http://www.planalto.gov.br/ccivil_03/leis/LCP/Lcp07.htm>. Acesso em: 06 nov. 2016.

- Portaria normativa $\mathrm{n}^{\mathrm{o}}$ 39, de 12 de dezembro de 2007. Institui o Programa Nacional de Assistência Estudantil - PNAES. Disponível em <http://portal.mec.gov.br/arquivos/pdf/portaria_pnaes.pdf $>$. Acesso em: 06 nov. 2016.

Decreto $\mathbf{n}^{\mathbf{o}} 6.096$ de 24 de abril de 2007. Dispõe sobre o Programa de Apoio a Planos de Reestruturação e Expansão das Universidades Federais REUNI. Brasília, 2007. Disponível em: < http://www.planalto.gov.br/ccivil_03/_ ato2007-2010/2007/decreto/d6096.htm>. Acesso em: 22 out. 2015.

2010a.

Constituição da República Federativa do Brasil de 1988. Brasília,

Decreto $\mathrm{n}^{\circ} \mathbf{7 . 2 3 4}$, de 19 de julho de 2010. Dispõe sobre o Programa Nacional de Assistência Estudantil - PNAES. Brasília, 2010b. Disponível em: <http://www.planalto.gov.br/ccivil_03/_Ato2007-2010/2010/Decreto/D7234. htm> Acesso em: 21 abr. 2016.

- Portaria $\mathrm{n}^{\mathrm{o}}$ 25, de 28 de dezembro de 2010. Dispõe sobre o Programa Nacional de Assistência Estudantil para as instituições de educação superior públicas estaduais - PNAEST. 2010c. Disponível em: <http://www. cmconsultoria.com.br/imagens/diretorios/diretorio14/arquivo2886.pdf $>$. Acesso em: 04 out. 2016. 
Lei de Diretrizes e Bases da Educação Nacional. Brasília, 1996. Disponível em <http://www.planalto.gov.br/ccivil_03/leis/L9394.htm>. Acesso em: 21 abr. 2016.

CHAVES, Vera Lúcia Jacob; AMARAL, Nelson Cardoso. Políticas de financiamento da educação superior no Brasil: o incentivo a privatização. In: JEZINE, Edineide; BITTAR, MARILUCE (Org.). Políticas de Educação Superior no Brasil: expansão, acesso e igualdade social. João Pessoa: Editora da UFPB, 2013. p. 35-55.

CURY, Carlos Roberto Jamil. A educação básica no Brasil. Educação \& Sociedade, v. 23, n. 80, p. 169-201, Especial set. 2002. Disponível em: < http:// www.cedes.unicamp.br>. Acesso em: 22 de out. 2015.

DUARTE, Clarice Seixas. A educação como um direito fundamental de natureza social. Educação \& Sociedade, Campinas, v. 28, n. 100 - Especial, p. 691-713, out. 2007. Disponível em <http://www.scielo.br/pdf/es/v28n100/a0428100. pdf $>$. Acesso em: 05 fev. 2016.

GIMENEZ, Felipe Vieira; MACIEL, Carina Elisabeth. A política de expansão na educação superior e os desafios da permanência. Anais... IX Seminário de Política e Administração da Educação da ANPAE Centro-Oeste, 14 a 16 de junho de 2016. Universidade Católica Dom Bosco (UCDB), Campo Grande/MS, p. 01-14, 2016.

INEP. Instituto Nacional de Estudos e Pesquisas Educacionais Anísio Teixeira. Resultados do Censo da Educação Superior 2014. Brasília: Instituto Nacional de Estudos e Pesquisas Educacionais Anísio Teixeira, 2015.

LIMA, Antonio Bosco de; MARQUES, Mara Rúbia Alves; SILVA, Sarita Medina. Reforma e qualidade da educação no Brasil. Revista HISTEDBR On-line, Campinas, n. Especial, mai. p.181-197, 2009. Disponível em: <http://www. histedbr.fe.unicamp.br/revista/edicoes/33e/art11_33esp.pdf $>$. Acesso em: 22 abr. 2016.

LIMA, Antonio Bosco de. Dez anos de LDB: anos de contínua reforma educacional. In: SILVA, Maria Vieira; MARQUES, Rúbia Alves Marques (Org.). LDB: balanços e perspectivas para a educação brasileira. 2. ed. Campinas, SP: Alínea, 2012. p. 52-59. 
MACIEL, Carina Elisabeth; SILVA, Maria das Graças Martins da; VELOSO, Tereza Christina Mertens Aguiar. Assistência Estudantil: a evolução de uma política pública e os significados no contexto da Educação Superior. In: SOUSA, José Vieira (Org.). Expansão e avaliação da educação superior brasileira: formatos, desafios e novas configurações. Brasília: Fino Traço, p. 255-276, 2015.

MACIEL, Carina Elisabeth et al. Acesso e permanência de estudantes na Universidade Federal de Mato Grosso do Sul: a expansão em questão. Relatório de Atividades, Campo Grande, p. 01-45, 2015.

. Discurso de inclusão e política educacional: uma palavra, diferentes sentidos. InterMeio: revista do Programa de Pós-Graduação em Educação, Campo Grande, MS, v.15, n.30, p.32-54, jul./dez. 2009.

MANCEBO, Deise. Políticas de educação superior. In: SILVA JÚNIOR, João dos Reis; SOUSA, José Vieira de; AZEVEDO, Mário Luiz Neves de; CHAVES, Vera Lúcia Jacob (Org.). Educação superior: internacionalização, mercantilização e repercussões em um campo de disputas. Belo Horizonte, MG: Fino Traço, p. 141-161, 2015.

MANCEBO, Deise; VALE, Andréa Araujo do; MARTINS, Tania Barbosa. Políticas de expansão da educação superior no Brasil 1995-2010. Revista Brasileira de Educação, Rio de Janeiro, v. 20, n. 60, p. 31-50, jan/mar 2015.

MELO, André Lins de; SANTOS, Elisangela de Jesus Ribeiro dos; ANDRADE, Gercília Pereira de. Ensino superior no Brasil: do elitismo colonial ao autoritarismo militar. In: Dermeval Saviani; José Claudinei Lombardi. (Orgs) UNICAMP. Seminário Nacional de Estudos e Pesquisas "História, Sociedade e Educação no Brasil". Anais... Campinas, SP: FE/UNICAMP: HISTEDBR, 2009. p. 01-19. Disponível em: < http://www.histedbr.fe.unicamp.br/acer_histedbr/seminario/ seminario8/trabalhos.htm>. Acesso em: 22 abr. 2016.

NUNES, Roseli Souza dos Reis; VELOSO, Tereza Christina Mertens Aguiar. Elementos que interferem na permanência do estudante na educação superior pública. In: XXIII Seminário Nacional da Rede UNIVERSITAS/ $\mathrm{Br}$ / Rede UNIVERSITAS/Br; Universidade Federal do Pará. Anais... 
Instituto de Ciências da Educação. Belém: UNIVERSITAS/Br; ICED/UFPA, 2015. p. 815-830. Disponível em: <http://www.obeduc.uerj.br/arquivos/ AnaisRedeUniversitas2705.pdf>. Acesso em: 27 ago. 2015.

OLIVEIRA, Dalila Andrade. Das políticas de governo a política de estado: reflexões sobre a atual agenda educacional brasileira. Educação \& Sociedade, Campinas, v. 32, n. 115, p. 323-337, abr.-jun. 2011. Disponível em: < http:/ /www. cedes.unicamp.br>. Acesso em: 16 fev. 2016.

PRIMÃO, Juliana Cristina Magnani. Permanência na educação superior pública: o curso de Enfermagem da Universidade Federal de Mato Grosso, Campus Universitário de Sinop. 2015. 191f. Dissertação (Mestrado em Educação). Programa de Pós-Graduação em Educação da UFMT — Universidade Federal de Mato Grosso, Cuiabá, 2015.

SANTOS, Kátia Silva. Políticas públicas educacionais no Brasil: tecendo fios. In: $25^{\circ}$ Simpósio Brasileiro de Política e Administração da Educação. $2^{\circ}$ Congresso Ibero-Americano de Política e Administração da Educação - ANPAE. Políticas Públicas e Gestão da Educação - construção histórica, debates contemporâneos e novas perspectivas. Anais... São Paulo - SP. p. 01-13. 2011. Disponível em: <http://www.anpae.org.br/simposio2011/cdrom2011/trabalhosCompletos01. htm $>$ Acesso em: 16 set. 2016.

SILVA, Maria das Graças Martins da; NOGUEIRA, Patrícia Simone. Expansão na educação superior e a política de democratização: avanços e contradições. In: SILVA, Maria das Graças Martins da. (Org.). Políticas Educacionais faces e interfaces da democratização. Cuiabá: EdUFMT, 2011. p. 13-37.

SGUISSARDI, Valdemar. Estudo diagnóstico da política de expansão da (e acesso à) educação superior no Brasil 2002-2012. Piracicaba, 2014.

\section{UNESCO. Declaração Mundial sobre Educação Superior no Século XXI:}

Visão e Ação. Conferência Mundial sobre Educação Superior, p. 01-09. 1998. Biblioteca Virtual de Direitos Humanos da USP. Disponível em: <http://www. direitoshumanos.usp.br/declaracao-mundial-sobre-educacao-superior-no-seculoxxi-visao-e-acao.html>. Acesso em: 16 de set. 2016. 
UNEMAT. Resolução no 020/2013-CONSUNI. Cria o Auxílio Alimentação para discentes dos cursos de Graduação da Universidade do Estado de Mato Grosso - UNEMAT. Disponível em: < http://www.unemat.br/legislacao/index. php?ac $=$ resolucoes $>$. Acesso em: 05 fev.2016.

UNEMAT. Resolução $\mathbf{n}^{\mathbf{o}}$ 021/2013-CONSUNI. Cria o Auxílio Moradia para discentes dos cursos de Graduação da Universidade do Estado de Mato Grosso - UNEMAT. Disponível em: < http://www.unemat.br/legislacao/index. php?ac $=$ resolucoes $>$. Acesso em: 05 fev.2016.

CARINA ELISABETH MACIEL é doutora em Educação pela UFMS. Professora no CCHS/UFMS e PPGEdu/UFMS. Pesquisadora da Rede Universitas/Br, com pesquisa do Observatório da Educação "Políticas de Expansão da Educação Superior no Brasil" e outra financiada pela Fundect/CNPq N¹4/2014 - PPP - MS: Política de Educação Superior no Brasil Pós-LDB/1996: Impactos na Região Centro-Oeste. Líder do Grupo de Estudos e Pesquisas em Políticas de Educação Superior/Mariluce Bittar (GEPPES/MB). E-mail: carina22em@ yahoo.com.br

ELIZETH GONZAGA DOS SANTOS LIMA é docente do Curso de Pedagogia e coordenadora do PPGEdu da Universidade do Estado de Mato Grosso. Pós-doutora em Educação com especificidade em Avaliação Educacional. Pesquisadora da Rede Universitas/Br, com pesquisa do Observatório da Educação "Políticas de Expansão da Educação Superior no Brasil". Líder do Grupo de pesquisa GEPAVE/CNPQ: Grupo de Estudos e Pesquisas em Avaliação Educacional. E-mail: elizeth@unemat.br

FELIPE VIEIRA GIMENEZ é graduado em Pedagogia pela UFMS e Mestrando do Curso de Pós-Graduação - Mestrado em Educação da UFMS (PPGEdu/ UFMS). É bolsista CAPES/MEC/Brasil. Integrante da Rede Universitas/Br, com pesquisa do Observatório da Educação "Políticas de Expansão da Educação Superior no Brasil" e outra financiada pela Fundect/CNPq N¹4/2014 - PPP - MS: Política de Educação Superior no Brasil Pós-LDB/1996: Impactos na Região Centro-Oeste. Participa do GEPPES/MB. E-mail: felippegimenezz@ gmail.com 